Published as: De Vos, J., T. Schwanen, V. Van Acker \& F. Witlox (2015) “How satisfying is the Scale for Travel Satisfaction?". Transportation Research F: Traffic Psychology and Behaviour. Vol. 29, pp. 121-130.

\title{
How satisfying is the Scale for Travel Satisfaction?
}

\section{Abstract}

The Satisfaction with Travel Scale (STS) has recently been developed to measure people's satisfaction with travel. It supposedly consists of two affective and one cognitive dimension. As there have only been a few tests of its reliability and structure to date, this paper reports new tests using data on leisure trips from Ghent (Belgium). Differences in the reliability and structure of the STS by transport mode - car, public transport, bicycling and walking - are also considered. Overall, the results suggest that the specification of a single underlying dimension for affect rather than two offers a superior fit to the Ghent data, both for all modes combined and for car use and cycling separately. For public transport and walking a three-dimensional structure is more appropriate although individuals items do not load on the two affective dimensions as expected. Differences between previous studies and ours are partly caused by differences in how two of the scale's items - alert/tired and confident/worried - are correlated with the other items. Future studies using the STS may want to adapt the structure of STS by omitting some items or replacing them with alternatives as this may reduce respondent burden and increase internal consistency of the STS.

Keywords: Travel satisfaction; Affect; Well-being; Transport mode; Reliability; Ghent; Belgium. 


\section{Introduction}

Well-being and travel satisfaction have recently attracted increased attention in transport-related research (De Vos et al., 2013). Over the past years authors have therefore developed scales to measure how people perceive their travel. The scale that has been applied most frequently to date is the Satisfaction with Travel Scale (STS). This is based on methods developed to measure subjective well-being (SWB) and was first used by Ettema et al. (2011). SWB is widely assumed to consist of two dimensions (Diener et al., 1985; Ettema et al., 2011, 2013): affective well-being refers to an individual's emotional state (i.e., intensity, frequency, and duration of positive and negative affect), and cognitive well-being pertains to an individual's assessment of his/her life in general (i.e., a cognitive judgment of satisfaction with life as a whole). The STS is designed using similar dimensions as SWB and can therefore be seen as a domain-specific version of SWB.

In the STS the items measuring affective well-being (i.e., emotions) during travel are based on the Swedish Core Affect Scale (SCAS) (Västfjäll et al., 2002; Västfjäll \& Gärling, 2007) and the core affect model by Russell $(1980,2003)$. According to the core affect approach, emotions can be decomposed into two underlying dimensions. Activation refers to the extent of arousal by environmental cues and varies from activated to deactivated. The second dimension is called valence and measures the extent of pleasure a person experiences; it ranges from positive to negative. Like the SCAS, the STS uses two sets of three adjective pairs to measure the intensity, frequency and duration of positive and negative feelings during a trip. The two sets are specific combinations of valence and activation i.e., positive activation/negative deactivation and positive deactivation/negative activation - and the respective adjective pairs are enthusiastic/bored, engaged/fed up and alert/tired, and calm/stressed, confident/worried and relaxed/hurried. The cognitive part of travel satisfaction is measured in the STS through a set of adverse statements regarding the trip made (i.e., travel was the best/worst I can think of, Travel was high/low standard and travel worked out/did not work out well). 
Although the core affect approach has strong roots in psychological research (e.g., Yik et al., 2011), not all scales try to measure the affective aspects of well-being by using the affect circumplex defined by a valence and activation dimension (Ettema et al., 2011; Russel, 1980, 2013). Since it is commonly assumed that the affective component of (hedonic) well-being consists of the presence of positive feelings and the absence of negative feelings (see, for instance, Diener, 2009), it could be argued that valence (ranging from negative to positive) is a more important dimension than activation (ranging from deactivation to activation) when measuring affective well-being. This train of thought has resulted in scales measuring the affective component of well-being by only using valence and not activation, including the commonly used Positive and Negative Affect Scale (PANAS) (Watson et al., 1988) and the more recent Scale of Positive and Negative Experience (SPANE) (Diener et al., 2010). It is therefore interesting to analyse the STS-items measuring affect during travel and see whether a subdivision of affects along the two constitutive dimensions of the affect circumplex is appropriate, or whether an alternative, such as combining all affective items into one dimension of valence, is more applicable.

So far studies have computed STS scores by averaging the scores across individual items for the three dimensions of positive activation/negative deactivation, positive deactivation/negative activation, and cognitive evaluation (Ettema et al., 2011, 2012, 2013; Friman et al., 2013; Olsson et al., 2013). Recently, Ettema et al. (2013) (using 256 Dutch car drivers), Friman et al. (2013) (using 951 residents from Stockholm, Göteborg and Malmö (Sweden)) and Olsson et al. (2012) (using 1000 public transport users from Karlstad and Göteborg (Sweden)) have tested the reliability of the STS with two affective and one cognitive dimension, using values of Cronbach's alphas and structural equation modelling (i.e., confirmatory factor analyses). These studies state that STS consists of three underlying dimensions. Although Ettema et al. (2013) and Friman et al. (2013) state that travel satisfaction is measured adequately by the aforementioned nine items, Olsson et al. (2012) suggests excluding two of the nine items from STS. Friman et al. (2013) have also analysed whether the 
structure of STS's underlying dimensions varies according to transport mode used, and their analysis on data from Stockholm, Göteborg and Malmö suggests this not to be the case.

Further tests on the underlying structure and reliability of the STS using different data are nonetheless desirable. Doing so, we will test whether dividing the affective dimension of STS in two sub dimensions (according to valence and activation) is the best choice, or whether other alternatives such as combining all affective components in one dimension (varying according to valence) is more appropriate. Not only is the STS likely to be used increasingly given the increasing interest in travel satisfaction among transport researchers; the original formulation also consists of nine items, which means a sizable burden for individual respondents. If the STS is embedded in a much broader (travel behaviour) study, or if satisfaction is measured for different types of trips in one and the same survey, then respondent burden is likely to be an issue. The possibility to reduce the length of STS should therefore be considered carefully. In this study we will test the reliability and analyse the underlying dimensions of the STS using Cronbach's alphas, correlation matrices and factor analyses for leisure trips in Ghent, Belgium. Given the considerable interest in the relationship between travel satisfaction and transport mode used, we will also consider whether the structure of the STS differs by mode of transport (car, public transport, bicycle, walking). The focus on travel satisfaction by transport mode follows from the observation in previous studies that the use of specific modes is amongst the strongest differentiators in the level of travel satisfaction. Various studies have shown that active travel generates the highest levels of travel satisfaction, while public transport users' experience is most negative (Abou-Zeid, 2009; De Vos et al., 2015; Duarte et al., 2010; Ettema et al., 2011; Friman et al., 2013; Olsson et al., 2013). Various studies have also indicated that other aspects of travel behaviour are associated with the level of travel satisfaction (De Vos et al., 2013; Ettema et al., 2010). These include trip duration (Ettema et al., 2012; see also Stutzer \& Frey, 2008); the activities people perform during a trip (Ettema et al., 2013); and the environmental conditions in which travel is undertaken. Unexpected events (delays), cleanliness, 
safety and social interaction affect satisfaction with public transport trips, while crowdedness and presence of trees/flowers are known to influence satisfaction with walking trips and levels of safety and congestion satisfaction with car trips (Ettema et al., 2013; see also Friman et al., 1998, 2001; Stradling et al., 2007).

\section{Data}

Data from an Internet survey on travel satisfaction, residential location choice and well-being are employed. We stratified Ghent's total population based on residential neighbourhood so that we can examine differences in travel behaviour, travel experience and so forth between people living in urban neighbourhoods and those in suburban neighbourhoods. Although not applicable to the current study, this distribution method makes it possible to use the residential neighbourhood as an explanatory variable in analyses seeking to explain variations in, for instance, transport mode choice and travel satisfaction. Invitations with a link to the Internet survey were distributed in five urban and seven suburban neighbourhoods in the city of Ghent, Belgium (250,000 inhabitants) in November-December 2012. The neighbourhoods were selected based on their physical characteristics: urban neighbourhoods are characterized by high densities, high diversities and a design favouring active travel, while suburban neighbourhoods have lower densities and diversities and higher levels of car accessibility. The 27,780 invitations that were distributed (one for every household in the selected neighbourhoods, covering about one fourth of all households in Ghent) eventually generated useable responses from 1,807 adults. While the recruitment method yielded a response rate of only $6.5 \%$, the important result is that, in socioeconomic and demographic terms, the participants are roughly comparable to the population of the selected neighbourhoods (Table 1). For more details on the neighbourhood selection and sampling method, see De Vos et al. (2015). For this study we excluded individuals with too many missing values and individuals giving identical 
scores for all nine items in the STS ('flatliners'), resulting in 1,411 respondents. Of these, $57.6 \%$ lived in urban and $42.4 \%$ in suburban neighbourhoods.

Table 1: Sample characteristics (Source: De Vos et al., 2015; Stad Gent, 2012)

\begin{tabular}{|c|c|c|c|c|c|}
\hline & $\begin{array}{c}\text { Total } \\
\text { respondents }\end{array}$ & $\begin{array}{l}\text { Urban } \\
\text { respondents } \\
\text { (survey) }\end{array}$ & $\begin{array}{l}\text { Urban } \\
\text { residents } \\
\text { (reference) }\end{array}$ & $\begin{array}{l}\text { Suburban } \\
\text { respondents } \\
\text { (survey) }\end{array}$ & $\begin{array}{c}\text { Suburban } \\
\text { residents } \\
\text { (reference) }\end{array}$ \\
\hline \multicolumn{6}{|l|}{ Age } \\
\hline $18-30$ & $22.3 \%$ & $32.6 \%$ & $31.4 \%$ & $8.2 \%$ & $12.3 \%$ \\
\hline 31-45 & $28.4 \%$ & $31.2 \%$ & $31.1 \%$ & $24.6 \%$ & $24.4 \%$ \\
\hline $46-60$ & $26.1 \%$ & $21.3 \%$ & $19.1 \%$ & $32.8 \%$ & $30.0 \%$ \\
\hline$>60$ & $23.1 \%$ & $14.9 \%$ & $18.4 \%$ & $34.4 \%$ & $33.3 \%$ \\
\hline \multicolumn{6}{|l|}{ Gender } \\
\hline Female & $45.7 \%$ & $48.8 \%$ & $49.5 \%$ & $41.4 \%$ & $51.0 \%$ \\
\hline Male & $54.3 \%$ & $51.2 \%$ & $50.5 \%$ & $58.6 \%$ & $49.0 \%$ \\
\hline \multicolumn{6}{|l|}{ Household type } \\
\hline Single & $25.9 \%$ & $38.7 \%$ & $45.0 \%$ & $9.6 \%$ & $12.2 \%$ \\
\hline Single parent & $4.1 \%$ & $4.7 \%$ & $5.8 \%$ & $3.5 \%$ & $7.5 \%$ \\
\hline Couple without children & $40.2 \%$ & $36.5 \%$ & $29.1 \%$ & $44.7 \%$ & $38.8 \%$ \\
\hline Couple with children & $29.8 \%$ & $20.1 \%$ & $20.1 \%$ & $42.2 \%$ & $41.4 \%$ \\
\hline \multicolumn{6}{|l|}{ Household size } \\
\hline Household members & 2.3 & 2.0 & 1.8 & 2.7 & 2.5 \\
\hline \multicolumn{6}{|l|}{ Household car ownership } \\
\hline 0 & $21.9 \%$ & $32.4 \%$ & $35.9 \%$ & $7.7 \%$ & $9.7 \%$ \\
\hline 1 & $52.6 \%$ & $54.4 \%$ & $52.5 \%$ & $50.3 \%$ & $55.5 \%$ \\
\hline$>1$ & $25.5 \%$ & $13.2 \%$ & $11.6 \%$ & $42.3 \%$ & $34.8 \%$ \\
\hline \multicolumn{6}{|l|}{ Household monthly net income } \\
\hline Low (< 1750 euro) & $17.9 \%$ & $9.9 \%$ & N/A & $24.1 \%$ & N/A \\
\hline Average (1750 - 3499 euro) & $49.4 \%$ & $49.4 \%$ & N/A & $49.3 \%$ & N/A \\
\hline High (3500+ euro) & $32.7 \%$ & $40.7 \%$ & N/A & $26.5 \%$ & N/A \\
\hline \multicolumn{6}{|l|}{ Education } \\
\hline Low (lower than bachelor degree) & $22.7 \%$ & $17.9 \%$ & N/A & $29.2 \%$ & N/A \\
\hline High (bachelor degree or higher) & $77.3 \%$ & $82.1 \%$ & N/A & $70.8 \%$ & N/A \\
\hline
\end{tabular}

For their most recent leisure trip respondents were asked to indicate to which extent they felt certain emotions, using exactly the same items as in previous STS studies to enable comparison: enthusiastic/bored, engaged/fed up and alert/tired for positive activation/negative deactivation; calm/stressed, confident/worried and relaxed/hurried for positive deactivation/negative activation; and travel was the best/worst I can think of; travel was high/low standard; and travel worked out/ 
did not work out well for the cognitive dimension of travel satisfaction. For all items respondents indicated how they experienced travel on 7-point scales, ranging from -3 (minimum/negative emotions or evaluation) to 3 (maximum/positive emotions or evaluation) (Fig. 1). Respondents were also asked to indicate the (main) transport mode used for the trip in question; 735 respondents (52.1\%) travelled by car, 137 (9.7\%) by public transport (bus/tram/metro), 276 (19.6\%) cycled and $263(18.6 \%)$ walked. A comparison of the survey data with data from a survey performed by the city of Ghent in 2010 (2000+ respondents; including information on travel mode choices for different types of trips) indicates that the mode shares in the current study are comparable to the modal split for leisure travel among the Ghent population at large (i.e., car: $49.5 \%$; public transport; $14.5 \%$; bicycling: 21.4\%; walking: 14.6\% (Stad Gent, 2012)). Nonetheless, walking trips are slightly overrepresented and public transport trips are slightly underrepresented in the current study.

Figure 1: The Satisfaction with Travel Scale

\begin{tabular}{|c|c|c|c|c|c|c|c|c|c|c|}
\hline $\begin{array}{c}\text { Two } \\
\text { dimensions }\end{array}$ & Three dimensions & Negative & -3 & -2 & -1 & 0 & 1 & 2 & 3 & Positive \\
\hline \multirow{6}{*}{$\begin{array}{l}\text { Affective } \\
\text { dimension }\end{array}$} & \multirow{3}{*}{$\begin{array}{c}\text { Positive activation } \\
\text { - Negative } \\
\text { deactivation }\end{array}$} & Bored & 0 & 0 & 0 & 0 & 0 & 0 & $\mathrm{O}$ & Enthusiastic \\
\hline & & Fed up & 0 & 0 & 0 & 0 & 0 & 0 & $\mathrm{O}$ & Engaged \\
\hline & & Tired & 0 & 0 & 0 & 0 & 0 & 0 & 0 & Alert \\
\hline & \multirow{3}{*}{$\begin{array}{c}\text { Positive } \\
\text { deactivation - } \\
\text { Negative activation }\end{array}$} & Stressed & $\mathrm{O}$ & 0 & 0 & 0 & 0 & 0 & $\mathrm{O}$ & Calm \\
\hline & & Worried & 0 & 0 & 0 & $\mathrm{O}$ & $\mathrm{O}$ & $\mathrm{O}$ & $\mathrm{O}$ & Confident \\
\hline & & Hurried & 0 & 0 & 0 & 0 & 0 & 0 & 0 & Relaxed \\
\hline \multirow{3}{*}{$\begin{array}{l}\text { Cognitive } \\
\text { dimension }\end{array}$} & \multirow{3}{*}{$\begin{array}{l}\text { Cognitive } \\
\text { evaluation }\end{array}$} & $\begin{array}{l}\text { Travel was worst } \\
\text { I can think of }\end{array}$ & 0 & 0 & 0 & $\mathrm{O}$ & $\mathrm{O}$ & 0 & $\mathrm{O}$ & $\begin{array}{c}\text { Travel was best I } \\
\text { can think of }\end{array}$ \\
\hline & & $\begin{array}{l}\text { Travel was low } \\
\text { standard }\end{array}$ & $\mathrm{O}$ & 0 & $\mathrm{O}$ & $\mathrm{O}$ & $\mathrm{O}$ & $\mathrm{O}$ & $\mathrm{O}$ & $\begin{array}{c}\text { Travel was high } \\
\text { standard }\end{array}$ \\
\hline & & $\begin{array}{l}\text { Travel did not } \\
\text { work out well }\end{array}$ & $\mathrm{O}$ & 0 & $\mathrm{O}$ & $\mathrm{O}$ & $\mathrm{O}$ & $\mathrm{O}$ & $\mathrm{O}$ & $\begin{array}{c}\text { Travel worked } \\
\text { out well }\end{array}$ \\
\hline
\end{tabular}

More than half of the respondents (51.2\%) stated that they performed their most recent leisure trip and activity the day they filled in the survey or the day before. The other part (48.8\%) performed their most recent leisure trip two days before they filled in the survey, or earlier (Table 2). The used retrospective measure could create distortions affecting the delayed recall and evaluation of the trip 
(Kahneman et al., 2004), especially among respondents who performed their most recent leisure trip several days before filling in the survey. Since we asked information about the most recent leisure trips, independent from the travel mode, and public transport is used for leisure trips among the sample reasonably often ( $9.7 \%$, see above), differences by transport mode in the number of days between when respondents performed these trips and when they filled out the survey are limited. Chi-square tests indicate that the differences by transport mode in number of days between when respondents performed these trips and when they filled out the survey are not significantly different at $p<0.05$ (the $p$-values for pairwise comparisons are as follows: car-public transport: $p=0.52$; carbicycling: $p=0.09$; car-walking: $p=0.10$; public transport-bicycling: $p=0.54$; public transportwalking: $p=0.78$; bicycling-walking: $p=0.69$ ). Memory effects are therefore unlikely to have affected travel satisfaction differentially across modes. Furthermore, we have tried to minimise memory distortions by excluding individuals with identical scores and too many missing values on the nine STS-items.

Table 2: Cross-tabulation of mode choice by the time respondents performed their most recent leisure activity

\begin{tabular}{lccccc|c}
\hline When did you perform your most recent leisure activity? & Car & $\begin{array}{c}\text { Public } \\
\text { transport }\end{array}$ & Bicycling & Walking & Total \\
\hline Today & 103 & 26 & 51 & 51 & 231 \\
Yesterday & 246 & 43 & 105 & 98 & 492 \\
Two days ago & 147 & 25 & 51 & 41 & 264 \\
Three days ago & 97 & 17 & 31 & 28 & 173 \\
More than three days ago & 142 & 26 & 38 & 45 & 251 \\
\hline Total & 735 & 137 & 276 & 263 & 1411 \\
\hline
\end{tabular}




\section{Item Analysis}

For all but one item, the average scores on the STS items across all transport modes fall between one and two (Table 3). This indicates that respondents are reasonably satisfied with their most recent leisure trip. The exception is alert/tired, for which the average is close to zero (0.22) and suggests that travel is often a (somewhat) tiring experience. The highest score (1.74) is for travel worked out/did not work out well, suggesting that respondents experienced few transport-related problems on their last leisure trip. Overall mean values have to be interpreted with some caution, however. This is because the distribution of scores is negatively skewed for all items (Table 4); the mean values are therefore slightly depressed by low values ('outliers'). All but one distribution are also peaked, indicating that a large amount of respondents gave the same score for most items. This is particularly the case for travel work out/did not work out well. The one clear exception is travel is best/worst I can think of, for which the kurtosis is -0.23 .

Table 3: Mean scores on the nine scales of STS by transport mode

\begin{tabular}{llcccc}
\hline Positive adjective/statement $\downarrow$ & Car & Public transport & Bicycling & Walking & All modes \\
\hline Enthusiastic & $1.25^{* *}$ & $0.89^{* *}$ & $1.45^{* *}$ & $1.49^{* *}$ & 1.31 \\
Engaged & $1.19^{* *}$ & $0.64^{* *}$ & 1.05 & 1.19 & 1.12 \\
Alert & 0.21 & $0.02^{* *}$ & 0.25 & $0.32^{*}$ & 0.22 \\
Calm & 1.46 & 1.32 & $1.30^{* *}$ & $1.60^{* *}$ & 1.45 \\
Confident & $1.42^{* *}$ & 1.22 & $1.21^{* *}$ & 1.39 & 1.36 \\
Relaxed & 1.37 & 1.22 & $1.26^{*}$ & $1.61^{* *}$ & 1.39 \\
Travel was best I can think of & $1.13^{* *}$ & $0.93^{* *}$ & 1.22 & $1.44^{* *}$ & 1.19 \\
Travel was high standard & $1.21^{* *}$ & $1.13^{*}$ & $1.38^{*}$ & $1.38^{*}$ & 1.27 \\
Travel worked out well & $1.68^{* *}$ & $1.46^{* *}$ & 1.77 & $2.00^{* *}$ & 1.74 \\
\hline
\end{tabular}

Mode-specific mean values are compared with the mean values of the three other modes combined using one sample t-tests.

statistically higher $(* p<0.1 ; * *<0.05)$ than the average value for the three other modes combined; statistically lower $\left({ }^{*} p<0.1 ;{ }^{* *} p<0.05\right)$ than the average value for the three other modes combined 
Table 4: Correlations, means, standard deviations, skewness, and kurtosis of the nine scales in STS

\begin{tabular}{lccccccccc}
\hline Positive adjective/statement $\downarrow$ & 1 & 2 & 3 & 4 & 5 & 6 & 7 & 8 & 9 \\
\hline 1. Enthusiastic & 1 & & & & & & & & \\
2. Engaged & 0.71 & 1 & & & & & & & \\
3. Alert & 0.39 & 0.37 & 1 & & & & & & \\
4. Calm & 0.49 & 0.46 & 0.26 & 1 & & & & & \\
5. Confident & 0.52 & 0.48 & 0.34 & 0.61 & 1 & & & & \\
6. Relaxed & 0.54 & 0.52 & 0.29 & 0.86 & 0.62 & 1 & & & \\
7. Travel was best I can think of & 0.38 & 0.33 & 0.21 & 0.38 & 0.37 & 0.39 & 1 & & \\
8. Travel was high standard & 0.48 & 0.38 & 0.22 & 0.40 & 0.40 & 0.41 & 0.72 & 1 & \\
9. Travel worked out well & 0.34 & 0.27 & 0.19 & 0.43 & 0.43 & 0.45 & 0.69 & 0.60 & 1 \\
\hline Mean & 1.31 & 1.12 & 0.22 & 1.45 & 1.36 & 1.39 & 1.19 & 1.27 & 1.74 \\
Standard deviation & 1.26 & 1.32 & 1.08 & 1.41 & 1.33 & 1.45 & 1.29 & 1.24 & 1.25 \\
Skewness & -0.65 & -0.62 & -0.32 & -1.02 & -0.81 & -0.94 & -0.38 & -0.56 & -1.15 \\
Kurtosis & 0.25 & 0.30 & 1.03 & 0.50 & 0.46 & 0.22 & -0.23 & 0.07 & 1.31 \\
\hline
\end{tabular}

$0.4 \leq$ Correlation coefficient $<0.6$

correlation coefficient $\geq 0.6$.

The mode-specific averages are in line with earlier research by showing that travel satisfaction, both affect and cognitive evaluation, is highest for walking and lowest for public transport trips (Table 3). The pattern is more mixed for cycling and car trips. Cycling on leisure trips makes people more stressed, worried and hurried but also more enthusiastic than people using other modes. Respondents using the car to reach their leisure activity are engaged and confident but are, however, not that enthusiastic and do not evaluate their trip very positively in comparison to respondents using alternative modes.

The nine items are all positively correlated with each other (at $p<0.01$ ) but clear differences in the strength of association are noticeable (Table 4). The alert/tired pair is the only item that has no correlation greater than 0.4 with any other item, and this is even the case for enthusiastic/bored and engaged/fed up - the other adjective pairs in the positive activation/negative deactivation dimension. In general, the greatest correlation coefficients can be found between items from the same dimension (i.e., positive activation/negative deactivation; positive deactivation/negative activation; and cognitive evaluation). All affective components (excepting alert/tired) have 
correlation coefficients above 0.4 with each other, indicating that positive activation factors are related with positive deactivation factors. The cognitive evaluation items are highly correlated with each other $(r>0.6)$ and seem to be higher correlated with positive deactivation than with positive activation items. Correlation coefficients found by Friman et al. (2013) and Olsson et al. (2012) are comparable but higher. They also found, for instance, the lowest correlation coefficients within the positive activation dimension for alert/tired.

\section{Structure of travel satisfaction}

This paper argues that a STS with two underlying dimensions - emotions and cognitive evaluation fits the Ghent data better than the three dimensional STS proposed by Ettema et al. (2013) and Friman et al. (2013). This will be demonstrated using factor analyses and Cronbach's alphas.

Tables 5 and 6 summarize the outcomes of two factor analyses on the nine items (principal axis factoring). An oblique rotation method (i.e., promax rotation) was used, allowing factors to be correlated with each other. This method has the advantage that (due to the oblique rotation) the correlations between the original variables and the rotated axes (i.e., factor loadings) are high. For this study it is important that the factors are highly correlated with the nine scales of STS, making it possible to analyse the relation between the underlying dimensions of STS. Since we want to explore the underlying factor structure of STS without favouring one hypothesis (e.g., two affective dimensions) over another (e.g., one affective dimension), we performed exploratory instead of confirmatory factor analyses. The three-factor solution in Table 5 explains $74.9 \%$ of the total variance and renders factors that are similar to the three underlying dimensions used by Ettema et al. (2013) and Friman et al. (2013). There are, however, at least two important differences between those studies and ours. First, with Pearson's correlation coefficients of $0.58-0.66$ the three underlying 
dimensions are more strongly associated with each other for the Ghent data. Secondly, our data confirm the idea that STS comprises three underlying dimensions only partially. This is because the eigenvalue for the positive activation/negative deactivation dimension is only 0.94 , while two items fail to confirm the hypothesized structure. The low loadings for confident/worried (0.48) on the positive deactivation factor and alert/tired (0.39) on the positive activation factor are in line with the correlation coefficients discussed above. On balance, the results for the three-factor solution are not entirely convincing.

The two-factor solution explains $64.5 \%$ of total variance, and a structure of a single factor for affect alongside cognitive evaluation is shown to appear; the correlation between the extracted factors is 0.66 (Table 6). All items on the emotions factor have positive loadings, although emotions associated with positive deactivation (calm/stressed, confident/worried, relaxed/hurried) load more heavily on the factor than those associated with positive activation (enthusiastic/bored, engaged/fed up, alert/tired). The cognitive evaluation factor is nearly identical to the factor with the same name in the three-factor solution. The two-factor solution is clearer than the three-factor solution as all factor loadings are rather high (lowest value: 0.48 ) and no items have a factor loading on the other factor that exceeds 0.2. Both factors also have an eigenvalue larger than one. For these reasons the twofactor solution is preferred. 
Table 5: Pattern matrix and correlation coefficients for the three-factor solution ${ }^{\text {a }}$

\begin{tabular}{|c|c|c|c|}
\hline $\begin{array}{l}\text { Factor } \rightarrow \\
\text { Positive adjective / statement } \downarrow\end{array}$ & $\begin{array}{c}\text { Cognitive } \\
\text { evaluation (CA) } \\
(4.50)^{\mathrm{b}}\end{array}$ & $\begin{array}{l}\text { Positive deactivation } \\
\text { (PD) } \\
(1.31)\end{array}$ & $\begin{array}{c}\text { Positive activation } \\
\text { (PA) } \\
(0.94)\end{array}$ \\
\hline Travel was best I can think of & 0.95 & & \\
\hline Travel worked out well & 0.76 & & \\
\hline Travel was high standard & 0.74 & & \\
\hline Calm & & 0.98 & \\
\hline Relaxed & & 0.87 & \\
\hline Confident & & 0.48 & 0.23 \\
\hline Enthusiastic & & & 0.84 \\
\hline Engaged & & & 0.82 \\
\hline Alert & & & 0.39 \\
\hline \multicolumn{4}{|l|}{ Pearson's correlation coefficients } \\
\hline CA and PD & 0.58 & & \\
\hline $\mathrm{CA}$ and $\mathrm{PA}$ & 0.59 & & \\
\hline PD and PA & 0.66 & & \\
\hline
\end{tabular}

${ }^{\mathrm{a}}$ Factor loadings between -0.2 and 0.2 are not retained for greater readability

${ }^{\mathrm{b}}$ Factor eigenvalue

Cronbach's alpha denotes the internal consistency (reliability), or average correlation of items in a survey instrument or scale, such as the STS. Its values range from 0 to 1 ; values above 0.7 are considered satisfactory and those exceeding 0.8 good (Santos, 1999). Table 7 indicates that for STS's three underlying dimensions as discerned by Ettema et al. (2011) the Cronbach's alphas are satisfactory (positive activation/negative deactivation) or good (positive deactivation/negative activation and cognitive evaluation). Nonetheless, the values increase for the two affective subscales when the adjective pairs alert/tired and confident/worried are excluded from, respectively, positive activation/negative deactivation and positive deactivation/negative activation. The two affective dimensions of STS would internally be more consistent if these adverse adjectives were excluded. 
Table 6: Pattern matrix and correlation coefficients for the two-factor solution ${ }^{\text {a }}$

\begin{tabular}{|c|c|c|c|}
\hline $\begin{array}{l}\text { Factor } \rightarrow \\
\text { Positive adjective / statement } \downarrow\end{array}$ & $\begin{array}{l}\text { Emotions } \\
(4.50)^{\mathrm{b}}\end{array}$ & $\begin{array}{l}\text { Cognitive evaluation } \\
\qquad(1.31)\end{array}$ & \\
\hline Relaxed & 0.84 & & \\
\hline Calm & 0.79 & & \\
\hline Confident & 0.68 & & \\
\hline Enthusiastic & 0.67 & & \\
\hline Engaged & 0.65 & & \\
\hline Alert & 0.48 & & \\
\hline Travel was best I can think of & & 0.97 & \\
\hline Travel worked out well & & 0.74 & \\
\hline Travel was high standard & & 0.73 & \\
\hline Pearson's correlation coefficient & 0.66 & & \\
\hline \multicolumn{4}{|c|}{$\begin{array}{l}{ }^{a} \text { Factor loadings between }-0.2 \text { and } 0.2 \text { are not retained for greater readability } \\
{ }^{b} \text { Factor eigenvalue }\end{array}$} \\
\hline & Positive activation & Positive deactivation & Cognitive evaluation \\
\hline Cronbach's Alpha & 0.73 & 0.87 & 0.86 \\
\hline \multicolumn{4}{|l|}{ Cronbach's alpha when excluding: } \\
\hline Enthusiastic & 0.51 & & \\
\hline Engaged & 0.54 & & \\
\hline Alert & 0.81 & & \\
\hline Calm & & 0.74 & \\
\hline Confident & & 0.92 & \\
\hline Relaxed & & 0.76 & \\
\hline Travel was best I can think of & & & 0.75 \\
\hline Travel was high standard & & & 0.83 \\
\hline Travel worked out well & & & 0.83 \\
\hline
\end{tabular}

In light of the factor analyses discussed above, Cronbach's alpha's have also been calculated for the STS with two underlying dimensions - one affective and the other cognitive (Table 8). Cronbach's alphas are good for both dimensions, and excluding adverse adjectives does not give higher values and greater internal consistency. In short, the affective element of STS is more reliable when all adverse adjectives are combined in one dimension than if two dimensions are specified. 
Table 8: Cronbach's alphas for emotions and cognitive evaluation

\begin{tabular}{lcc}
\hline & Emotions & Cognitive evaluation \\
\hline Cronbach Alpha & 0.85 & 0.86 \\
\hline Cronbach's alpha when excluding: & 0.82 & \\
Enthusiastic & 0.83 & \\
Engaged & 0.85 & \\
Alert & 0.81 & \\
Calm & 0.82 & \\
Confident & 0.80 & \\
Relaxed & & 0.75 \\
\hline Travel was best I can think of & & 0.83 \\
Travel was high standard & & 0.83 \\
Travel worked out well & & \\
\hline
\end{tabular}

Given the correlations among the extracted factors in the two- and three-factor solutions, it is no surprise that a factor analysis extracting a single factor that combines the affective and cognitive elements of travel satisfaction also renders plausible results. With an eigenvalue of 4.5 the single factor explains $50.0 \%$ of the total variation, and the lowest factor loading is 0.41 for alert/tired (as before, principal axis factoring and promax rotation have been used). The Cronbach's alpha is 0.87 if a single dimension is assumed, and increases marginally to 0.88 if alert/tired is excluded. Although these results indicates that emotions associated with a trip and its cognitive evaluation are clearly related with each other, we prefer to maintain a distinction between affective and cognitive components, in keeping with the prevailing conceptualizations of SWB (see above) and the idea that assessing such statements as travel was the best/worst I can think of, travel was of high/low standard and travel worked out/did not work out well invokes the slower and more deliberative system 2 of the brain (Kahneman 2003, 2011) to a greater extent than the affective adjective pairs (whose evaluation is likely to rely more on the more instinctive and emotional system 1). 


\section{Structure of mode-specific travel satisfaction}

So far the analysis has shown that the underlying dimensions of travel satisfaction are partly dependent on the empirical data that have been used, and that marked differences in travel satisfaction levels exist between different transport modes. This raises the possibility that the STS structure differs according to the transport mode used. Therefore, factor analyses (principal axis factoring, promax rotation) on the STS's nine items have been conducted for leisure trips undertaken by car, public transport, cycling, and walking separately (Table 9).

Table 9: Factor analysis of travel satisfaction, by transport mode (factor loadings in brackets)

\begin{tabular}{|c|c|c|c|c|}
\hline & Car & Public Transport & Bicycling & Walking \\
\hline $\begin{array}{l}\text { Number of } \\
\text { factors }\end{array}$ & 2 & 3 & 2 & 3 \\
\hline \multirow[t]{6}{*}{ Factor 1} & Relaxed (0.78) & Enthusiastic (0.97) & Relaxed (0.89) & Calm (0.92) \\
\hline & Enthusiastic (0.76) & Alert (0.76) & Calm (0.81) & Relaxed (0.87) \\
\hline & Engaged (0.75) & Engaged (0.71) & Confident $(0.71)$ & Confident (0.58) \\
\hline & Calm (0.75) & Confident (0.48) & Enthusiastic (0.61) & Alert (0.45) \\
\hline & Confident (0.61) & & Engaged (0.53) & \\
\hline & Alert (0.45) & & Alert (0.44) & \\
\hline \multirow[t]{3}{*}{ Factor 2} & Best imaginable (0.94) & Best imaginable (0.87) & Best imaginable (0.94) & Best imaginable (0.98) \\
\hline & Worked well (0.80) & High standard (0.83) & High standard (0.86) & Worked well (0.70) \\
\hline & High standard (0.73) & Worked well (0.76) & Worked well (0.75) & High standard (0.54) \\
\hline \multirow[t]{2}{*}{ Factor 3} & & Calm (0.99) & & Enthusiastic $(0.84)$ \\
\hline & & Relaxed (0.91) & & Engaged (0.79) \\
\hline
\end{tabular}

The number of extracted factors depends on which factors had an eigenvalue greater than one. Two factors have been extracted for car and cycling. As when all modes combined (Table 6), the first factor gathers the affective items and the second pertains to cognitive evaluation. However, positive deactivation/negative activation items (calm/stressed, confident/worried, and relaxed/hurried) load stronger on the first factor for bicycling than for car use. This can be explained with reference to earlier results that bicyclists are significantly less relaxed, calm and confident than the average traveller (Table 3). 
The STS for public transport use and walking has three underlying dimensions but these are not the same as those proposed by Ettema et al. (2011). For public transport the first factor gathers all elements of positive activation/negative deactivation, as well as the item confident/worried; while the third factor comprises the items calm/stressed and relaxed/hurried. It is not immediately clear why confidence and arousal are more strongly correlated for public transport and this would need to be explored further (using qualitative methods); however, this result may reflect that availability in space and time of public transport is more constrained than for the other modes considered and that therefore greater levels of planning and attention are required when public transport trips are undertaken. The first factor of walking contains all elements of positive deactivation/negative activation and the positive activation/negative deactivation item alert/tired; while the third factor assembles the positive activation/negative deactivation emotions enthusiastic and engaged. These results for public transport and walking are consistent with the correlation coefficients in Table 3. They indicate that transport mode choices, and the resulting variations in travel satisfaction, imply differences in the sub-scale structure of the STS.

Reliability tests with Cronbach's alphas differentiated by transport mode (Table 10) give results that are comparable results to those for all modes combined (Tables 7-8). For car use and bicycling the Cronbach's alphas are good $(>0.8)$ when all six affective items are combined, but they increase slightly when alert/tired is excluded altogether. The positive deactivation/negative activation dimension is also reliable for all travel modes; however, all Cronbach's alphas increase if confident/worried is excluded. Reliability is weakest for the positive activation/negative deactivation dimension. The internal consistency of this dimension is only acceptable or good for respectively car use and public transportation use. For bicycling and walking, the internal consistency of positive deactivation is marginally unacceptable (Cronbach's alpha <0.7). However, all Cronbach's alphas increase to acceptable levels if alert/tired is deleted. The cognitive evaluation dimension is reliable (Cronbach's alpha $>0.8$ ) for all modes and cannot be increased by excluding an items. 
Table 10: Cronbach's alphas for all modes and for all dimensions of STS

\begin{tabular}{lcccc}
\hline & Car & $\begin{array}{c}\text { Public } \\
\text { Transport }\end{array}$ & Bicycling & Walking \\
\hline Cronbach's alpha of all six emotions combined & 0.85 & 0.88 & 0.83 & 0.84 \\
Excluded variable increasing Cronbach's alpha & Alert (0.87) & $/$ & Alert (0.85) & $/$ \\
\hline Cronbach's alpha of positive activation & 0.74 & 0.84 & 0.68 & 0.69 \\
Excluded variable increasing Cronbach's alpha & Alert (0.84) & Alert (0.85) & Alert (0.74) & Alert (0.80) \\
\hline Cronbach's alpha of positive deactivation & 0.87 & 0.88 & 0.88 & 0.86 \\
Excluded variable increasing Cronbach's alpha & Conf. (0.93) & Conf. (0.95) & Conf. (0.92) & Conf. (0.89) \\
\hline Cronbach's alpha of cognitive evaluation & 0.86 & 0.87 & 0.88 & 0.81 \\
Excluded variable increasing Cronbach's alpha & $/$ & $/$ & $/$ & $/$ \\
\hline
\end{tabular}

The structure of satisfaction with travel may also differ according to transport mode use for theoretical reasons. Scholarship in geography and sociology has long since argued that emotions are shaped by both neurological processes within the corporeal body and the physical, social, cultural and political environments and contexts through which move as part of everyday life (e.g., Davidson et al., 2005; Anderson, 2006; Ahmed, 2010). Given that different travel modes provide travellers with specific situations that involve different levels of physical activation and exposure to social interaction and cultural symbols and 'frictions' (weather, uneven road surfaces, etcetera) associated with the physical environment, the affective and cognitive dimensions of travel satisfaction can differ qualitatively according to transport mode. For instance, active travel and especially car use protect travellers against undesired contact with other (unknown) travellers, which is much less the case for public transport users (Bissell, 2010; Hiscock et al., 2002). Furthermore, physical exercise has been shown to increase happiness (due to the release of dopamine), improve mood and reduce anxiety (Kringelbach \& Berridge, 2009; Penedo and Dahn, 2005), which likely increases travel satisfaction of walking and cycling. It has also been argued that, more than other modes, walking is therapeutic because it improves mental health, allows social relationships with other humans and animal companions to be cemented or developed, and permits direct and relatively unmediated engagement with places and environments on the move (Gatrell, 2013). 
The results presented in Tables 9-10 reinforce the earlier suggestion that the alert/tired and confident/worried pairs do not fully fit the dimensions of positive activation/negative deactivation and positive deactivation/negative activation. Previous studies on the STS also suggest that the alert/tired and confident/worried items do not relate to the STS's underlying dimensions as strongly as other affective items; however, the differences appear to be more pronounced for the Ghent data. Friman et al. (2013) and Olsson et al. (2012) use structural equation models (confirmatory factor analyses) to assess the psychometric properties of the STS. In most cases path coefficients from confident/worried and especially alert/tired to the accompanying affective STS dimensions are lower than path coefficients from the other items, even although the precise results differ between trips to and from work and according to the transport mode used and the city where data have been collected (Friman et al., 2013). In this context it should also be noted that Olsson et al. (2012) deleted the items alert/tired and confident/worried from their analysis because these items had fairly high factor loadings $(>0.3)$ on more than one of the three factors that capture the three dimensions of STS.

The fact that alert/tired and confident/worried do not fully fit, respectively, the positive activation/negative deactivation and positive deactivation/negative activation dimension may reflect that these adverse adjective pairs appear not to have been tested extensively before they were introduced by Ettema et al. (2011). Västfjäll et al. (2002) and Västfjäll \& Gärling (2007) indicate that calm/stressed and relaxed/hurried (in the original articles described as calm/anxious and relaxed/nervous) are reliable indicators of the positive deactivation/negative activation dimension in the SCAS. The same is true for enthusiastic/bored and engaged/fed up (originally framed as interested/bored and engaged/indifferent) as measures of positive activation/negative deactivation. Those authors did not, however, include the alert/tired and confident/worried in their analysis. They did include awake/sleepy and optimistic/pessimistic in the SCAS but these adjective pairs do strictly speaking not measure the same emotional experiences as alert/tired and confident/worried do. As 
these two adjective pairs in STS have been added more recently, their effects on overall scale reliability are more uncertain and need further examination.

\section{Conclusion and Discussion}

While previous research has indicated that the Satisfaction with Travel Scale (STS) consists of three underlying dimensions (Ettema et al. 2013; Friman et al. 2013), this study has found that two underlying dimensions - one for emotions and the other for cognitive evaluation - fits the data from Ghent, Belgium better than a three-dimensional STS. Another key difference between our study and Friman et al.'s (2013) research is that we do find evidence that the underlying structure of the STS depends on the transport mode that is used. Whereas the number of dimensions underlying the STS is identical across modes and the factor loadings for individual items differ hardly per mode, we find differences in both the number of dimensions and factor loadings. For leisure trips by car or bicycle, the specification of two factors - again one for emotions and the other for cognitive evaluation gives the best fit, although a three-factor solution is superior for public transport use and walking. For the latter two modes the items that load onto the two factors for emotions do not conform to the positive deactivation/negative activation and negative deactivation/positive activation dimensions posited by Ettema et al. (2010) and Västfjäll et al. (2002).

Despite variations in the way the structure of the STS has been evaluated across studies, this difference appears to be partly a consequence of differences in data. Not only in the specific geographical context from which data stem, there is also a notable difference in the type of trips considered: the study in Sweden by Friman et al. (2013) has focused on trips to and from work/school and that in the Netherlands by Ettema et al. (2013) on all trips, whereas our data only cover trips undertaken for leisure purposes. One implication of our findings is that the structure of 
dimensions at the basis of the STS is essentially an empirical question; the structure proposed by Ettema et al. (2011) cannot be assumed to be universally valid or applicable. Some data might support the idea that the STS consists of three dimensions, while other data might suggest two underlying dimensions.

Although our results show clear differences between transport modes in the structure of STS, and differ from previous studies analysing STS, all reliability tests (both in this study and in previous studies (Friman et al., 2013; Olsson et al., 2012)) indicate that the adjective pairs confident/worried and especially alert/tired do not fully fit the affective dimension of STS, irrespective of whether this dimension is divided in two sub-dimensions or not. Although combining all six items related to emotions into a single dimension is a satisfactory option that produces high levels of internal consistency for our data, it could be interesting to replace alert/tired and confident/worried with alternative adjective pairs that are more successful in capturing the positive activation/negative deactivation and positive deactivation/negative activation dimensions proposed by the core affect approach (Russell, 1980, 2003). Alternatively, these items can also be replaced by items that are more closely related to the valence dimension, so the affective dimension of STS would mainly capture negative versus positive emotions during travel with only small variations in activation. Examples of such items could be elated/gloomy or upset/contented (Russel, 2003); however, reliability tests of possible new items are necessary. Changes along these lines would result in a strong(er) relation between travel satisfaction and the prevailing hedonic understanding of wellbeing, where the affective component refers to the presence of positive feelings and the absence of negative feelings (e.g., Diener, 2009). It is also possible to exclude the adverse adjectives alert/tired and confident/worried items from the STS altogether, and only maintain the highly correlated relaxed/hurried, calm/stressed items for positive deactivation/negative activation and enthusiastic/bored, engaged/fed up for positive activation/negative deactivation. This would reduce the number of items in the scale from nine to seven, and has the additional benefit that respondent 
burden will be reduced. This is particularly appealing in cases where the STS is used to evaluate satisfaction with multiple (kinds of) trips or the scale is embedded in a much broader survey of travel/activity behaviour. Future research should also test whether such a reduced STS actually decreases respondent burden.

There exist, then, many different ways in which the STS can be developed further. Subsequent research should try to increase internal consistency of the different dimensions of STS, whether or not with one or two affective dimensions. This can be done by reconsidering the items for measuring the affective elements of satisfaction with travel and/or by reducing the overall number of items and hence minimizing respondent burden.

\section{Acknowledgements}

This research has been funded by the Research Foundation - Flanders (FWO), grant G013212N. The authors are grateful to the peer reviewers for their insightful comments on earlier versions of the manuscript.

\section{References}

Abou-Zeid, M. (2009). Measuring and Modeling Activities and Travel Well-being (doctoral dissertation). Massachusetts Institute of Technology, Cambridge, MA.

Ahmed, S. (2009). The Promise of Happiness. Duke University Press, Durham, N.C. 
Anderson, B. (2006). Becoming and being hopeful: towards a theory of affect. Environment and Planning D, 24 (5), 733-752.

Bergstad, C.J., Gamble, A., Gärling, T., Hagman, O., Polk, M., Ettema, D., Friman, M., \& Olsson, L.E. (2011). Subjective well-being related to satisfaction with daily travel. Transportation, 38 (1), 1-15.

Bissell, D. (2010). Passenger mobilities: affective atmospheres and the sociality of public transport. Environment and Planning D, 28 (2), 270-289.

Davidson, J., Bonndi, L., \& Smith, M. (2005). Emotional Geographies. Ashgate, Aldershot.

De Vos, J., Mokhtarian, P.L., Schwanen, T., Van Acker, V., \& Witlox, F. (2015). Travel mode choice and travel satisfaction: bridging the gap between decision utility and experienced utility. Transportation, in press.

De Vos, J., Schwanen, T., Van Acker, V., \& Witlox, F. (2013). Travel and subjective well-being: a focus on finding, methods and future research needs. Transport Reviews, 33 (4), 421-442.

Diener, E. (2009). The Science of Well-Being: The Collected Works of Ed Diener, Volume 1. Springer, Dordrecht.

Diener, E., Emmons, R.A., Larsen, R.J., \& Griffen, S. (1985). The satisfaction with life scale. Journal of Personality Assessment, 49 (1), 71-75. 
Diener, E., Wirtz, D., Tov, W., Kim-Prieto, C., Choi, D.-W., Oishi, S., \& Diener-Biswar, R. (2010). New well-being measures: short scales to assess flourishing and positive and negative feelings. Social Indicators Research 97 (2), 143-156.

Duarte, A., Garcia, C., Giannarakis, G., Limão, S., Polydoropoulou, A., \& Litinas, N. (2010). New approaches in transportation planning: happiness and transport economics. Netnomics, 11 (1), 5-32. Ettema, D., Friman, M., Gärling, T., Olsson, L.E., \& Fujii, S. (2012). How in-vehicle activities affect work commuters' satisfaction with public transport. Journal of Transport Geography, 24, 215-222.

Ettema, D., Gärling, T., Eriksson, L., Friman, M., Olsson, L.E., \& Fujii, S. (2011). Satisfaction with travel and subjective well-being: development and test of a measurement tool. Transportation Research Part F, 14 (3), 167-175.

Ettema, D., Gärling, T., Olsson, L.E., \& Friman, M. (2010). Out-of-home activities, daily travel, and subjective well-being. Transportation Research Part A, 44 (9), 723-732

Ettema, D., Gärling, T., Olsson, L.E., Friman, M., \& Moerdijk, S. (2013). The road to happiness: measuring Dutch car drivers' satisfaction with travel. Transport Policy, 27, 171-178.

Friman, M., Fujii, S., Ettema, D., Gärling, T., \& Olsson, L.E. (2013). Psychometric analysis of the satisfaction with travel scale. Transportation Research Part A, 48, 132-145.

Friman, M., Edvardsson, B., \& Gärling, T. (1998). Perceived service quality attributes in public transport: inferences from complaints and negative critical incidents. Journal of Public Transportation, 2 (1), 69-91. 
Friman, M., Edvardsson, B., \& Gärling, T. (2001). Frequency of negative critical incidents and satisfaction with public transport services. Journal of Retailing and Consumer Services, 8 (2), 95-104.

Gatrell, A.C. (2013). Therapeutic mobilities: walking and 'steps' to wellbeing and health. Health \& Place, 22, 98-106.

Hiscock, R., Macintyre, S., Kearns, A., \& Ellaway, A. (2002). Means of transport and ontological security: Do cars provide psycho-social benefits to their users? Transportation Research Part D, 7 (2), 119-135.

Kahneman, D. (2003). Maps of bounded rationality: psychology for behavioral economics. American Economic Review, 93 (5), 1449-1475.

Kahneman, D. (2011). Thinking, Fast and Slow. Allen Lane, London.

Kahneman, D., Krueger, A.B., Schkade, D.A., Schwarz, N., \& Stone, A.A. (2004). A survey for characterizing daily life experience: the day reconstruction method. Science 306 (5702), 1776-1780.

Kringelbach, M.L., \& Berridge, K.C. (2009). Towards a functional neuroanatomy of pleasure and happiness. Trends in Cognitive Sciences, 13 (11), 479-487.

Olsson, L.E., Friman, M., Pareigis, J., \& Edvardsson, B. (2012). Measuring service experience: Applying the satisfaction with travel scale in public transport. Journal of Retailing and Consumer Services, 19 (4), 413-418. 
Olsson, L.E., Gärling, T., Ettema, D., Friman, M., \& Fujii, S. (2013). Happiness and satisfaction with work commute. Social Indicators Research, 111 (1), 255-263.

Penedo, F.J., \& Dahn, J.R. (2005). Exercise and well-being: a review of mental and physical health benefits associated with physical activity. Current Opinion in Psychiatry, 18 (2), 189-193.

Russell, J.A. (1980). A circumplex model of affect. Journal of Personality and Social Psychology, 39, $1161-1178$.

Russell, J.A. (2003). Core affect and the psychological construction of emotion. Psychological Review, $110,145-172$

Santos, J.R.A. (1999). Cronbach's alpha: a tool for assessing the reliability of scales. Journal of Extension, 37 (2), available at: http://www.joe.org/joe/1999april/tt3.html.

Stad Gent (2012). G3nt_1n_cijfer5. Available at: http://gent.buurtmonitor.be. (Last accessed in August 2013).

Stradling, S.G., Anable, J., \& Carreno, M. (2007). Performance, importance and user disgruntlement: a six-step method for measuring satisfaction with travel modes. Transportation Research Part A, 41 (1), $98-106$

Stutzer, A., \& Frey, B.S. (2008). Stress that doesn't pay: the commuting paradox. Scandinavian Journal of Economics, 110 (2), 339-366. 
Västfjäll, D., Friman, M., Gärling T., \& Kleiner, M. (2002). The measurement of core affect: a Swedish self-report measure. Scandinavian Journal of Psychology, 43 (1), 19-31.

Västfjäll, D., \& Gärling, T. (2007). Validation of a Swedish short self-report measure. Scandinavian Journal of Psychology, 48 (3), 233-238.

Watson, D., Clark, L.A., \& Tellegen, A. (1988). Development and validation of brief measures of positive and negative affects: the PANAS scales. Journal of Personality and Social Psychology 54 (6), 1063-1070.

Yik, M., Russel, J.A., \& Steiger, J.H. (2011). A 12-Point circumplex structure of core affect. Emotion, 11 (4), 705-731. 